\title{
What are beyond Mindsponge?
}

\author{
Minh-Hoang Nguyen \\ Centre for Interdisciplinary Social Research / Phenikaa University \\ Yen Nghia, Ha Dong, Hanoi 100803, Vietnam \\ January 13,2021
}

When I wrote a review of Pham and Vuong's book to express my affection after reading the first chapter [1], an idea popped up in my mind. It is whether I can explain economic activities using the Mindsponge mechanism [2,3].

In the first chapter, I could see the distinction between Pham and Vuong's book and other similar books. While other books' first chapters explain Vietnam's economic contexts or economic terminology, this book provides a broad overview of the global economy at the time. The overview helped me realize that what I think enormous is just a small part of a more enormous and complex system. In other words, Vietnam's economy is a component of the global economic system, so it cannot be explained solely by the entities within the economy itself and by the interaction with other economies within the global economic system.

The Mindsponge mechanism's primary function is to explain the learning and unlearning processes of an individual. It assumes that the external environment surrounds a sponge comprising of a mindset and a comfort zone. The external environment can be interpreted in many forms, but to me, it is a multi-layered system. Within that system, there are myriad individuals with dissimilar mindsponge processes. Those individuals can gather and form entities with higher hierarchical order, such as institutions, organizations, or teams. All the individuals and institutions/organizations/teams within a certain boundary continue forming a country. Thus, not only can the external environment change an individual's values, but an individual's values can also affect the surrounding environment because the individual is a part of the system. 


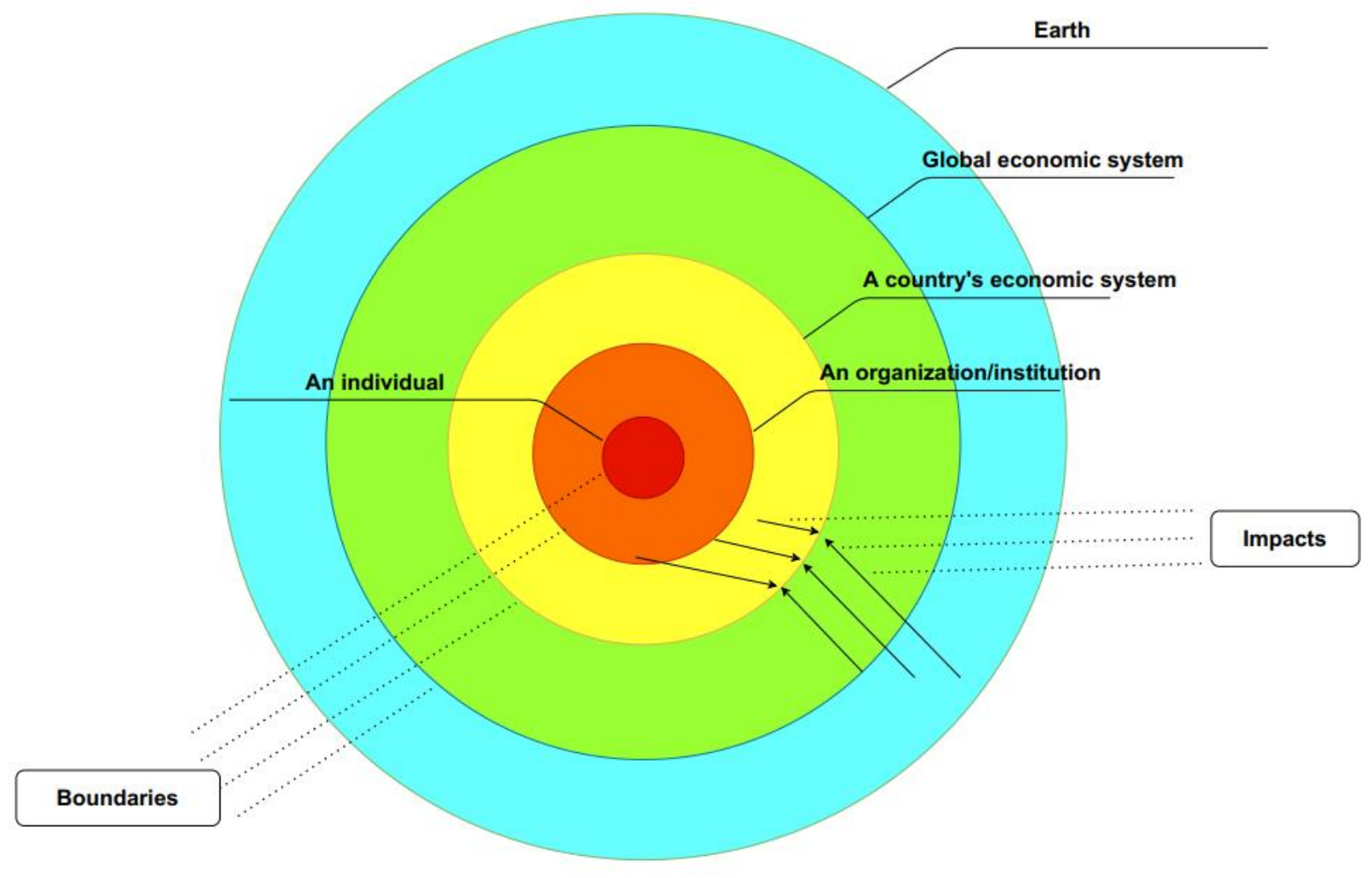

Figure 1: The sponge for economic activities

Based on this interpretation, I assume that the global economic system (green zone) is a part of the Earth system (blue zone) since all the economic activities are performed and fueled by the Earth's resources. There are national economic systems (yellow zone) of countries participating in the global trading network within the global economic system. Such economic systems will interact through trade and investment, which eventually impacts each other through tariffs, trade, and investment policies. I call these impacts a national economic system's external impacts. Each national economic system comprises many economic organizations (orange zone) and individuals (red zone), with each individual's and economic organization's action creates a certain impact on the system. I call these impacts a national economic system's internal impacts (see Figure 1).

The size and shape of any national economic system are simultaneously affected by both internal and external impacts. Specifically, the size is the total economic capacities and capabilities of all the organizations and individuals within the system. In contrast, the shape represents the production system, resource allocation, and distribution of goods and services within the country. 
Both of them are affected by multifaceted aspects (e.g., culture, technological and educational attainment, etc.) of institutions/organizations, individuals, and environmental resources within the system and other actors beyond the system.

I completely acknowledge that there are still many limitations with the proposed concept and my interpretation, but it is better to have a start than to keep it as zero. Hopefully, I can make the idea more transparent and concrete in the future so that it can be used to explain many contemporary phenomena, such as COVID-19, climate change, and other socio-economic and environmental issues [4-9]. I welcome constructive comments from all colleagues for improving the idea.

Last few words, all my thoughts here come after I read only the first chapter of the book. I am so excited to learn and be inspired more in the next few chapters.

\section{References}

[1] Phạm Minh Chính, Vương Quân Hoàng. (2009). Kinh tế Việt Nam: Thăng trầm và đột phá. Nxb Chính trị Quốc gia, Hà Nội.

[2] Quan-Hoang Vuong. (2016). Global mindset as the integration of emerging socio-cultural values through mindsponge processes: A transition economy perspective. In J. Kuada (Ed.), Global Mindsets: Exploration and Perspectives (pp. 109-126). London: Routledge.

[3] Quan-Hoang Vuong \& Nancy K. Napier. (2015). Acculturation and global mindsponge: an emerging market perspective. International Journal of Intercultural Relations, 49, 354-367.

[4] Phạm Minh Chính, Vương Quân Hoàng. (2008). Bối cảnh tài chính Việt Nam 1997-1998 và 2007-2008: Khoảng cách và biến đối. Nghiên cứu Kinh tế, 48(7), 3-24.

[5] Viet-Phuong La, et al. (2020). Policy response, social media and science journalism for the sustainability of the public health system amid the COVID-19 outbreak: The Vietnam lessons. Sustainability, 12(7), 2931.

[6] Quan-Hoang Vuong, et al. (2018). Cultural additivity: behavioural insights from the interaction of Confucianism, Buddhism and Taoism in folktales. Palgrave Communications, 4(1), 143. 
[7] Quan-Hoang Vuong, Manh-Tung Ho, Hong-Kong T. Nguyen, \& Minh-Hoang Nguyen. (2019). The trilemma of sustainable industrial growth: Evidence from a piloting OECD's Green city. Palgrave Communications, 5(1), 1-14.

[8] Quan-Hoang Vuong. (2021). The semiconducting principle of monetary and environmental values exchange. Economics and Business Letters, 10, forthcoming.

[9] Quan-Hoang Vuong, et al. (2020). On how religions could accidentally incite lies and violence: folktales as a cultural transmitter. Palgrave Communications, 6(1), 82. 